\title{
The Asymmetric Effects of OIL Shocks ON AN OIL-EXPORTING ECONOMY*
}

\author{
Omar Mendoza \\ Central Bank of Venezuela \\ DAVID VERA \\ Kent State University
}

We estimate the effects of unexpected changes in oil prices on output for the case of Venezuela, an oil-exporting economy. Following Hamilton (2003), Lee et al.: (1995), and Mork (1989), we estimate measures of oil shocks and determine the effect of these shocks on the Venezuelan economy. Our results suggest that oil shocks have had positive and significant effects on output growth in Venezuela during the period 1984:1-2008:3. In line with previous findings for other countries, our results suggest that the Venezuelan economy is more responsive to increases in oil prices than to unexpected decreases. Our results are robust to an alternative measure of oil price shocks derived by using 'Kilian's (2009) exogenous OPEC oil production shock series.

JEL: C22, E32

Keywords: Oil Shocks, Output Fluctuations, Nonlinear Estimation

\section{INTRODUCTION}

How industrialized economies, mostly net oil importers, respond to oil shocks is well documented. For instance, output growth in the U.S. is more responsive to unexpected increases in oil prices than to unexpected decreases. This asymmetric result is evidence of a nonlinear relationship between oil prices and output in the U.S. economy. However, little research has been done to establish how unexpected changes in oil prices affect an oil-exporter economy, such as Venezuela.

An important consideration in determining the effects of oil shocks on the Venezuelan economy is the identification of the exogenous component in oil-price

\footnotetext{
* Juan Pablo Montero and two anonymous referees have provided very useful suggestions. The Central Bank of Venezuela Research Department provided the data used in this paper. All remaining errors are ours.

Email: dvera@kent.edu
} 
changes. In this paper, we explicitly estimate a measure of oil shocks and determine the output growth's response. Hamilton (2003)' suggests measures of oil shocks for the U.S. economy. We estimate similar measures for the Venezuelan economy and determine that the adjusted residual of a GARCH model of real oil prices seems to best approximate oil shocks to the Venezuelan economy. We also determine that in 1984:1-2008:3 unexpected changes in oil prices had on average a positive and significant effect on output growth. Also, in line with previous findings, our results suggest that the Venezuelan economy is more responsive to unexpected increases in oil prices than to decreases.

In Section 2, we discuss some of the most relevant literature. Section 3 describes the alternative measures of oil shocks and the theoretical background. In Section 4, we estimate the effect of oil shocks on the Venezuelan economy. Section 5 discusses the robustness of our model. In Section 6, we conclude and discuss possible extensions.

\section{Related Literature}

Most of the previous research on oil shocks and output has focused on the U.S. economy. In particular, a significant number of articles have pointed to a nonlinear relationship between output and oil prices in the U.S. The nonlinear relationship between output and oil prices has had different explanations. For instance, Loungani (1986)' and Davis (1987), who were the first to report evidence of nonlinearity, suggested that oil shocks may cause sectoral shifts with costly reallocation of resources. 'Mork (1989)' found that when estimating separate coefficients on increases and decreases of oil prices, the coefficient on decreases were statistically not different from zero. Lee et al. $(1995)$ found that a better forecast of GDP could be obtained by adjusting the oil price increase by the standard deviation of price volatility. Hamilton (2003), further studied the nonlinearity using a flexible parametric model and found support for the findings of Lee et al. (1995). More recently, evidence of a nonlinear relationship between output and oil prices has also been reported for other OECD countries in Mork (1989); Cuñado and de Gracia (2003); Jiménez-Rodríguez and Sánchez (2005).

More recently, another string in the literature has been developed as an alternative to the identification of oil shocks used by Hamilton (2003) and Lee $e t$ al. (1995). Kilian (2008), Kilian (2009), and Kilian and Vigfusson (2009) point to the potential endogeneity in the estimation of the effects of oil shocks on the U.S. economy and use a measure of oil shocks based on a structural near-VAR model of the real price of crude oil. In Kilian (2009), the methodology used in the identification of structural shocks to the real price of oil relies on delay restrictions that, according to the author, are economically plausible at only the monthly frequency. Kilian (2009) develops a methodology that allows the separation of the innovations on oil prices into three components: oil supply shocks, aggregate demand shocks, and oil-specific demand shocks. By separating the source of oil price shocks in these three components, Kilian (2009)' concludes that most of the 
unexpected fluctuations in oil prices are due to aggregate demand shocks and oilspecific demand shocks. We address the potential endogeneity of our measure of oil shocks by incorporating the oil supply measure developed by 'Kilian (2009)'.

Among the research on oil-exporting countries, Tazhibayeva et al.(2008) find that oil shocks mainly affect the economic cycle in oil-exporting economies through their own fiscal policy. By estimating a VAR on a panel of oil exporting countries, the authors are able to estimate fiscal impulses that, in their model, capture transmission oil shocks to the economy. Different from their work, we look at only one country, Venezuela, which Tazhibayeva et al. (2008) do not include in their sample. In our research, which has a narrower scope, we are able to estimate country-specific oil shocks, and determine their effect on the oil and nonoil sectors of the economy. Baldini (2005) analyzes fiscal policy in Venezuela during 1991-2003. In line with our results, the author finds that cyclical volatility of the non-oil sector GDP is greater than the volatility of the oil sector GDP. Closer to our work, Arreaza et al. (2003) develop a small-scale macroeconomic model for Venezuela. Using their model, estimated for the period 1989-2001, the authors conduct simulation experiments to determine the effect of different shocks on inflation, output, exchange rates and interest rates. When looking at the effect of a shock in public expenditure, which could be due to an unexpected increase in oil prices, the authors find a positive and significant, albeit short, effect on output. Although their results are in line with our findings, the authors do not estimate oil shocks separately and do not look at the possible asymmetric effect of oil shocks on output growth.

\section{Alternative Measures of Oil Shocks}

This section describes the different measures of oil shocks used in the literature. The methodology developed by Hamilton (2003), Lee et al. (1995), and Mork (1989) focuses on the identification of unexpected changes to oil prices and their effects on the U.S. economy ${ }^{1}$. After the estimation of the oil shocks, an OLS regression is used to determine the effect of the oil shocks on aggregate output. This methodology has two advantages. First, we introduce only the exogenous component of the change in the price of oil into the OLS regression. Second, we introduce the nonlinearity in the model by using a measure of oil shocks as a regressor. The following measures of oil shocks have been identified in the existing literature.

1) Mork (1989):

$$
o_{t}^{+}= \begin{cases}0 & \text { if } o_{t} \leq 0 \\ o_{t} & \text { if } o_{t}>0,\end{cases}
$$

where $o_{t}$ is the percentage change in the nominal price of oil.

\footnotetext{
${ }^{1}$ Some extensions of these models have been used to estimate the effect on OECD countries.
} 
2) Lee et al. (1995):

$o_{t}^{ \pm}$is a measure of adjusted volatility in the increases in the real price of oil ${ }^{2}$.

$$
o_{t}^{ \pm}= \begin{cases}0 & \text { if } \frac{o_{t}^{R}}{\sqrt{h_{t}}} \leq 0 \\ \frac{o_{t}^{R}}{\sqrt{h_{t}}} & \text { if } \frac{o_{t}^{R}}{\sqrt{h_{t}}}>0,\end{cases}
$$

where $o_{t}^{R}$ is the real price of oil; $\sqrt{h_{t}}$ is estimated from the following $\operatorname{GARCH}(1,1)$ :

$$
\begin{aligned}
& o_{t}^{R}=\beta_{0}+\beta_{1} o_{t-1}^{R}+\beta_{2} o_{t-2}^{R}+\beta_{3} o_{t-3}^{R}+\beta_{4} o_{t-4}^{R}+e_{t} \\
& e_{t}=\sqrt{h_{t} v_{t}} \text { with } v_{t} \sim N(0,1) h_{t} \\
& h_{t}=C_{0}+\gamma e_{t-1}^{2}+\mu h_{t-1}
\end{aligned}
$$

The change in the real price of oil, $o_{t}^{R}=o_{t}-\Delta \ln p_{t} ; o_{t}$, is the percentage change in the nominal price of oil and $\Delta \ln p_{t}$ is the inflation rate.

3) Hamilton (2003):

Define $o_{t}^{\#}$ as the amount by which the nominal price of oil in quarter $t$ exceeds the highest value of the past 12 quarters. If the nominal price of oil in quarter $t$ does not exceed the highest value of the past 12 quarters, $o_{t}^{\#}$ equals zero. Hamilton (2003), indicates that this accounts for the increments that represent corrections in the price of oil and not unexpected shocks.

\subsection{Benchmark model}

To measure the effect of oil shocks on aggregate output, Hamilton (2003) estimates:

$$
y_{t}=\alpha_{0}+\sum_{i=1}^{4} \beta_{t-i} y_{t-i}+\sum_{i=1}^{4} \delta_{t-i} o_{t-i}^{\text {shock }}+\varepsilon_{t}
$$

where $o_{t-i}^{\text {shock }}$ can be any of the alternative measures of shocks described in Section 3 and $y_{t}$ is the growth rate of real GDP.

\footnotetext{
${ }^{2}$ We use the residuals of a regression where the dependent variable is the real price of oil.
} 


\subsection{Which is the best measure of shocks?}

Given the different metrics of oil shocks available, the following test can help determine the best measure of shocks. Hamilton (2003) indicates that even though the measures of shocks are nonlinear functions of oil prices, they are linear functions of the parameter estimates of equation (1). In fact, the benchmark model can be expressed as follows.

$$
y_{t}=\alpha_{0}+\delta^{\prime} z_{t}+\varepsilon_{t}
$$

Equation (1) is a specific case of equation (2), where $z_{t}$ can be defined as $\left[y_{t-1}, y_{t-2}, y_{t-3}, y_{t-4}, o_{t-1}^{\text {shock }}, o_{t-2}^{\text {shock }}, o_{t-3}^{\text {shock }}, o_{t-4}^{\text {shock }}\right]$.

In equation (2), $y_{t-1}$ is the annualized quarterly growth rate of GDP in period $t-i$ and $o_{t-i}^{\text {shock }}$ can be any of the alternative measures of shocks described in Section 3. The linearity test proposed by Hamilton (2003) is based on the comparison of equation (2):

$$
y_{t}=\alpha_{0}+\delta^{\prime} z_{t}+\lambda m x_{t}+\varepsilon_{t}
$$

where $x_{t}=\left[o_{t-1}, o_{t-2}, o_{t-3}, o_{t-4}\right], o_{t-i}$ is the change in oil prices in period $t-i$ and $m$ is the value of the random field described by Hamilton $(2003, \mathrm{p} .14)$.

The intuition behind this is that by testing a null hypothesis $\lambda=0$, we can determine if $z_{t}$ adequately captures the nonlinear relationship between $y_{t}$ and $o_{t-j}$. Hamilton's $(2003)$ results yield the measure proposed by Lee $e t$ al., $\left(o_{t}^{ \pm}\right)$, as the most appropriate nonlinear estimate of oil shocks' effect on aggregate output.

\section{RESUlts}

According to the Energy Information Administration: "Venezuela is one of the world's largest exporters of crude oil and the largest in the Western Hemisphere. In 2006, the country was the sixth-largest net oil exporter in the world. The oil sector is of central importance to the Venezuelan economy: it accounts for more than three-quarters of total Venezuelan export revenues, about half of total government revenues, and around one-third of total gross domestic product (GDP).'

Following, Stock and Watson (2002) we calculated the volatility of oil prices, shown in Figure 1. The figure illustrates large swings in volatility during the sample period. 
FIGURE 1

OIL-PRICE VOLATILITY

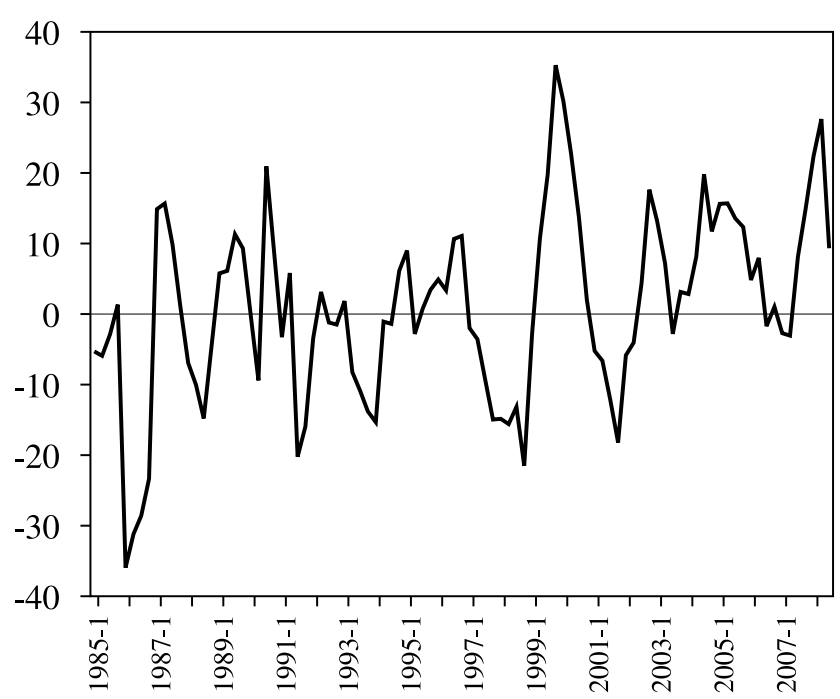

Source: BCV (Banco Central de Venezuela), authors calculation.

\subsection{Oil shocks' effects on the Venezuelan Economy}

To estimate the measure of oil shocks, we recall that our measure of shocks should capture the unexpected swings in oil prices. We were able to calculate a measure similar to the one proposed by Lee et al. (1995). We use the real price of oil as a starting variable and estimate the following model $^{3}$.

$$
o_{t}^{v}=\beta_{0}+\beta_{1} o_{t-1}^{v}+\beta_{2} o_{t-2}^{v}+\beta_{3} o_{t-3}^{v}+\beta_{4} o_{t-4}^{v}+e_{t}
$$

where $o_{t}^{v}$ is the real price of Venezuela oil and $\sqrt{h_{t}}$ is estimated through a $\operatorname{GARCH}(1,1)$ :

$$
e_{t}=\sqrt{h_{t} v_{t}} v_{t} \sim N(0,1) h_{t}
$$

$$
h_{t}=C_{0}+\gamma e_{t-1}^{2}+\mu h_{t-1}
$$

\footnotetext{
${ }^{3}$ We obtained similar results when the nominal price of oil was used.
} 
The oil-shock measure can be defined as $o_{t}^{\text {shock }}=\frac{e_{t}}{\sqrt{h_{t}}}$, the normalized residual of equation (4).

Figure 2 shows the West Texas Intermediate (WTI) in US\$, the reference value used by the Venezuelan government to estimate oil revenues, as well as a measure of oil shocks. Oil prices have been erratic during the sample period, experiencing a significant run up since 2002, which led to a historic high in the summer of 2008 .

FIGURE 2

\section{OIL-PRICE AND OIL SHOCKS}

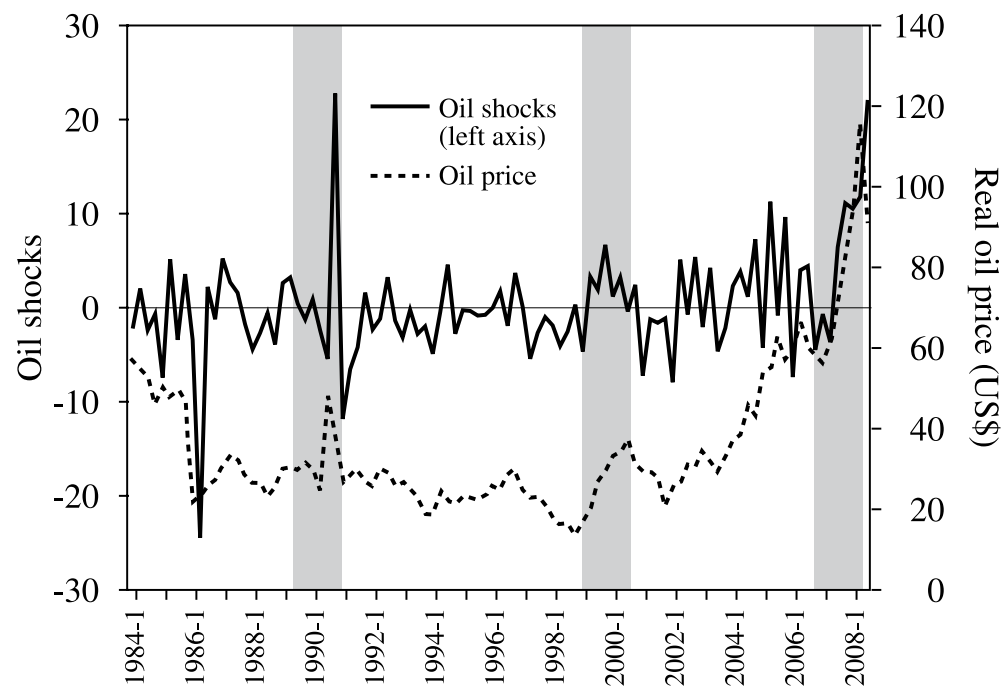

Source: BCV.

We examine quarterly growth of real total GDP, real oil-sector GDP, and real nonoil-sector GDP for the period 1984:2 to 2008:3.4 When we introduced our measure of oil shocks into equation (1), we obtained the following results for total GDP.

$$
\begin{aligned}
y_{t}= & \underset{(0.747)}{1.626}-\underset{(0.096)}{0.290} y_{t-1}-\underset{(0.010)}{0.212} y_{t-2}-\underset{(0.101)}{0.083} y_{t-3}+\underset{(0.099)}{0.276} y_{t-4} \\
& -\underset{(0.129)}{0.125} o_{t-1}^{\text {shock }}+\underset{(0.59)}{0.077} o_{t-2}^{\text {shock }}+\underset{(0.138)}{0.231 o_{t-3}^{\text {shock }}}+\underset{(0.747)}{1.626} o_{t-4}^{\text {shock }}
\end{aligned}
$$

The effect of oils shocks is positive and significant. The $p$-value of the test on the oil-shock coefficient being zero is 0.021

\footnotetext{
${ }^{4}$ Given the importance of oil in the Venezuelan economy, the Central Bank of Venezuela estimates GDP for the oil and nonoil sectors separately. Our results are also robust to yearly growth rate.
} 
When we look at oil GDP, we obtain the following results:

$$
\begin{aligned}
y_{t}^{\text {oil }}= & \underset{(0.857)}{-1.602}-\underset{(0.104)}{0.346} y_{t-1}^{\text {oil }}-\underset{(0.111)}{0.379} y_{t-2}^{\text {oil }}-\underset{(0.112)}{0.004} y_{t-3}^{\text {oil }}-\underset{(0.1065)}{0.062} y_{t-4}^{\text {oil }} \\
& -\underset{(0.153)}{0.005} o_{t-1}^{\text {shock }}-\underset{(0.156)}{0.066} o_{t-2}^{\text {shock }}+\underset{(0.161)}{0.091} o_{t-3}^{\text {shock }}+\underset{(0.161)}{0.386} o_{t-4}^{\text {shock }} .
\end{aligned}
$$

The $p$-value of the test on the oil-shock coefficient being zero is 0.09 .

For nonoil GDP,

$$
\begin{aligned}
y_{t}^{\text {noil }}= & \underset{(0.818)}{-1.582}-\underset{(0.096)}{0.283} y_{t-1}^{\text {noil }}-\underset{(0.100)}{0.184} y_{t-2}^{\text {noil }}-\underset{(0.100)}{0.116} y_{t-3}^{\text {noil }}-\underset{(0.099)}{0.298} y_{t-4}^{\text {noil }} \\
& -\underset{(0.143)}{0.105} o_{t-1}^{\text {shock }}-\underset{(0.146)}{0.067} o_{t-2}^{\text {shock }}+\underset{(0.153)}{0.234} o_{t-3}^{\text {shock }}+\underset{(0.155)}{1.019} o_{t-4}^{\text {shock }} .
\end{aligned}
$$

The effects of oil shocks are positive and significant. The $p$-value associated with oil shocks is 0.027 .

Interestingly the effect of oil shocks is always significant. However, the effect is more substantial on the nonoil GDP than on the oil GDP. This result is driven by the fact that the oil revenues generated by the sale of Venezuelan oil by a state-owned company go back into the economy through public spending. On the other hand, oil GDP is determined by the amount of oil the government decides to produce, which may be unrelated to current market conditions.

\subsection{Nonlinear effect of oil shocks in the Venezuelan Economy}

Next, we look at the effect of unexpected oil-price increases, which has been the standard definition of oil shocks for oil-importer economies. In order to shed light on this issue, we redefine an oil shock as:

$$
o_{t}^{\text {shock-pos }}= \begin{cases}0 & \text { if } o_{t}^{\text {shock }} \leq 0 \\ o_{t}^{\text {shock }} & \text { if } o_{t}^{\text {shock }}>0\end{cases}
$$

where $o_{t}^{\text {shock }}$ is the normalized residual of Model (4).

We introduce the measure of shocks, $o_{t}^{\text {shock-pos }}$, into the models for total GDP, oil GDP, and nonoil GDP. In the case of total GDP,

$$
\begin{aligned}
y_{t}= & \underset{(1.007)}{0.228}-\underset{(0.100)}{0.270} y_{t-1}-\underset{(0.103)}{0.224} y_{t-2}-\underset{(0.104)}{0.081} y_{t-3}+\underset{(0.101)}{0.277} y_{t-4} \\
& -\underset{(0.211)}{0.245} o_{t-1}^{\text {shock-pos }}+\underset{(0.217)}{0.196} o_{t-2}^{\text {shock-pos }}+\underset{(0.232)}{0.211 o_{t-3}^{\text {shock-pos }}}+\underset{(.238)}{.564} o_{t-4}^{\text {shock-pos }} .
\end{aligned}
$$

The overall test of significance on $o_{t-i}^{\text {shock-pos }}$ for $i=1,2,3$ and 4 , yields a coefficient of 0.725 with a p-value of 0.07 . 
In the case of the oil GDP, the coefficient on the unexpected positive increases in oil prices is also positive but with a greater $p$-value, 0.09. In the case of the nonoil GDP, the coefficient is also positive and the $p$-value on the test of overall significance is 0.07 .

\section{ROBUSTNESS}

An important assumption in our measure of shock is that it clearly captures the exogenous unexpected changes in oil price. The issue of endogeneity for the case of the U.S. has been studied by Kilian (2009). Given the size of the U.S. economy, it is important to differentiate unexpected changes in oil prices due to changes in the demand of oil from changes in oil prices due to changes in supply of oil. Kilian's (2009) findings indicate that most of the real oil-price increases since the mid-1970s are due to increases in the demand for oil. Furthermore, the most recent increases in the price of oil can be traced to global aggregate demand shocks. However, there may be concerns that, even in our case, the assumption of endogeneity may be too strong. In particular, at times when the Venezuelan oil production was dramatically cut, oil prices responded to this supply shock. For example, 'Kilian (2008)' notes that the oil industry strike of December 2002 in Venezuela led to a drop in production of 2.3 million barrels a day, or $3.4 \%$ of world production at the time. The measure of oil shocks developed by Hamilton (2003), $o_{t}^{\#}$, reflected an increase in crude oil prices $20 \%$ above the previous 3 -year high.

In order to verify that our results are robust to potential endogeneity, we use an alternative approach to clean oil-price fluctuations from changes in oil prices due to shocks on the supply of oil. Kilian (2009) develops a methodology that separates the innovations on oil prices into three components: oil supply shocks, aggregate demand shocks, and oil-specific demand shocks. By separating the source of oil-price shocks in these three components, Kilian (2009) concludes that most of the unexpected fluctuations in oil prices are due to aggregate demand shocks and oil-specific demand shocks. In principle, our measure of oil shocks derived in Section 4.1 would include all three different types of innovations. One way to control for the oil-supply shocks would be to regress our Venezuela real oil-price series on a measure of oil supply shocks. Theoretically, the residual on this regression should include global aggregate demand shocks and oil-specific demand shocks, which are exogenous to the Venezuelan oil price. As an alternative to the oil shocks defined in Section 4, we estimate the following regression.

$$
o_{t}^{v}=\lambda_{0}+\lambda_{1} o_{t-1}^{\text {supply-shock }}+\lambda_{2} o_{t-2}^{\text {supply-shock }}+\lambda_{3} o_{t-3}^{\text {supply-shock }}+\lambda_{4} o_{t-4}^{\text {supply-shock }}+e_{t},
$$

where,$o_{t}^{\text {supply-shock }}$ is the series of exogenous oil-supply shocks from Kilian (2009) ${ }^{5}$.

5 Kilian $\overline{-}(\overline{2008})$ provides a series on exogenous OPEC oil-production shocks, including the Venezuelan oil industry strike during the period 2002-2003. This series is available at URL: http://www-personal.umich.edu/ 1kilian/oilshock.txt. 
This alternative oil-price shock, $o^{\text {Kilian }}$, can be defined as the residual of equation 11. Figure 3 shows the two oil-shock series: $o^{\text {shocks }}$ (oil-price shock (1)), estimated earlier, and $o^{\text {Kilian }}$ (oil-price shock (2)). As expected, at times of oil-supply disruption (grey shaded area) oil-price shock (2), which theoretically only includes aggregate demand shocks and oil-specific demand shocks, is systematically lower than oil-price shock (1). In the case of Venezuela, it is important to separate the source of the unexpected change in oil price. For instance, during the oil industry strike in Venezuela in 2002, as expected, oil-price shock (1) is higher than oilprice shock (2). In order to check the robustness of our results from Section 4, we proceed to estimate the effect of our new measure of oil shocks, $o^{\text {Kilian }}$, on real GDP for the period 1984:2-2004:3. ${ }^{6}$ Our results are robust to this alternative measure of oil shocks. When we re-estimate equation (1), we find that the effect of oil shocks, $o^{\text {Kilian }}$, is positive and significant. The $p$-value associated with $o^{\text {Kilian }}$ is 0.10 . It is important to emphasize that these results can be considered a lower bound since our measure of oil shocks, $o^{\text {Kilian }}$, is cleaned of all oil-supply shocks. Ideally, we would like to have a measure of oil shocks that is orthogonal only to the Venezuelan oil-supply shocks.

FIGURE 3

ALTERNATIVE OIL SHOCKS

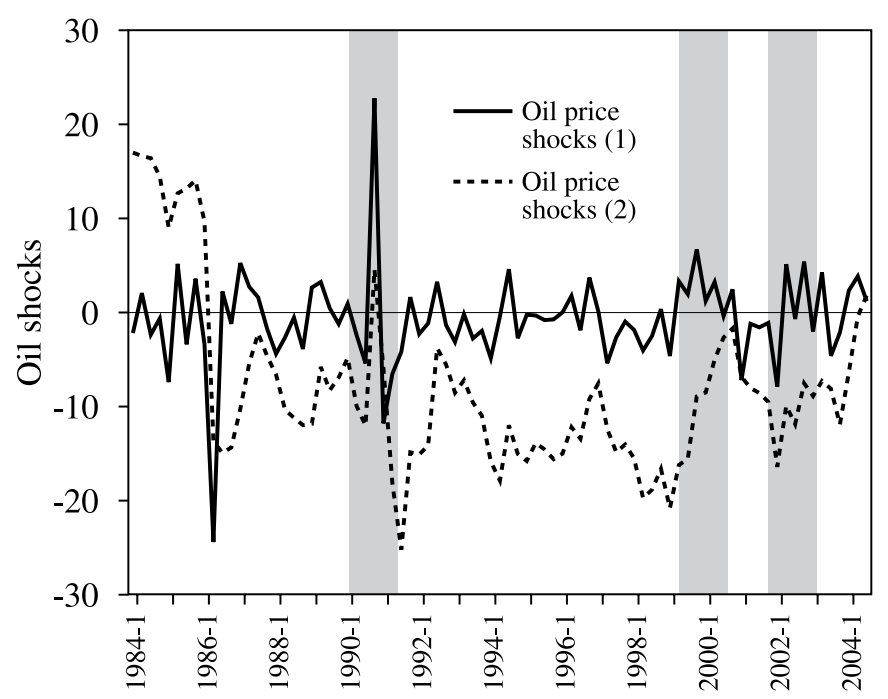

Source: authors calculation.

${ }^{6}$ Our oil price measure, $o^{\text {Kilian }}$, can only be estimated until 2004:3 since Kilian's $(2009)$ measure of oil-supply shocks is only available until 2004:3 


\section{CONCLUSION}

We determine that oil shocks, measured as unexpected changes in oil prices, have had a positive and significant effect on the Venezuelan economy. We also find that the unexpected increases in oil prices have had a greater effect on output than the unexpected decreases had. In line with previous findings in the literature, (Hamilton, 2003) we also find that in the case of an oil exporter, oil shocks have asymmetric effects on output growth. However, as expected, the effect of unexpected increases in oil prices is positive and significant. Our results are also robust to a measure of oil shocks that considers price disruptions due to exogenous oil-supply shocks driven by OPEC political events (Kilian, 2009).

\section{REFERENCES}

Arreaza, A., E. Blanco, and M. Dorta (2003), "A Small Scale Macroeconomic Model for Venezuela". Series de Documento de Trabajo 43, Banco Central de Venezuela.

Baldini, A. (2005), "Fiscal Policy and Business Cycles in an Oil-Producing Economy: The Case of Venezuela. IMF Working Papers 05/237, International Monetary Fund.

Cuñado, J. and F.P. de Gracia (2003), "Do Oil Price Shocks Matter? Evidence for some European Countries. Energy Economics, 25(2):137-154.

Davis, S.J. (1987), "Allocative Disturbances and Specific Capital in Real Business Cycle Theories". American Economic Review, 77(2):326-332.

Hamilton, J.D. (2003), "What is an Oil Shock?". Journal of Econometrics, 113:363-398.

Jiménez-Rodríguez, R. and M. Sánchez (2005), “Oil Price Shocks and Real GDP Growth: Empirical Evidence for Some OECD Countries". Applied Economics, 32(2):201-228.

Kilian, L. (2008), "Exogenous Oil Supply Shocks: How Big Are They and How Much Do They Matter for the U.S. Economy?" The Review of Economics and Statistics, 90(2):216-240.

Kilian, L. (2009), "Not All Oil Price Shocks Are Alike: Disentangling Demand and Supply Shocks in the Crude Oil Market". American Economic Review, 99(3):1053-1069.

Kilian, L. and R.J. Vigfusson (2009), "Pitfalls in Estimating Asymmetric Effects of Energy Price Shocks". International Finance Discussion Papers 970, Board of Governors of the Federal Reserve System (U.S.).

Lee, K., N. Shawn, and R. Ratti (1995), "Oil Shocks and the Macroeconomy: The Role of Price Variability”. Energy Journal, 16:39-56.

Loungani, P. (1986), "Oil Price Shocks and the Dispersion Hypothesis". The Review of Economics and Statistics, 68(3):536-539.

Mork, K.A. (1989), "Oil and the Macroeconomy when Prices Go Up and Down: An Extension of Hamilton's Results". Journal of Political Economy, 97:740-744.

Stock, J. H. and M.W. Watson (2002), "Has the Business Cycle Changed and Why?" NBER Working Papers 9127, National Bureau of Economic Research, Inc.10

Tazhibayeva, K., A.Ter-Martirosyan, and A.M. Husain (2008), "Fiscal Policy and Economic Cycles in Oil-Exporting Countries". IMF Working Papers 08/253, International Monetary Fund. 